\title{
Synthesis N-Doped Activated Carbon from Sugarcane Bagasse for $\mathrm{CO}_{2}$ Adsorption
}

\author{
Randy Yusuf Kurniawan, Irsandi Dwi Oka Kurniawan, Lukman Atmaja, and Nurul Widiastuti
}

\begin{abstract}
Nitrogen-doped activated carbon (SBACN) was synthesized from sugarcane bagasse waste as acarbon source and urea as nitrogen source through potassium hydroxide (KOH) activation for $2 \mathrm{~h}$ at high temperature via two step methods. The synthesized SBCN was characterized using X-Ray Diffraction (XRD), Scanning Electron Microscope (SEM), and Fourier Transform Infrared (FTIR). The results showed that the SBCN has low degree crystallinity and graphitization with highly developed micropores due to synergistik activation effect of $\mathrm{KOH}$ and urea. These characteristics provide an important contribution to carbon dioxide adsorption capacity, which can reach up to $11,20 \% \mathrm{wt}$ and this value is higher than pristine activated carbon. The results indicating that the presence of this nitrogen functionalities is found to have a beneficial influence on the carbon dioxide adsorption characteristic in standart condition and exhibit considerable potential in solid adsorption.
\end{abstract}

Keywords-Nitrogen-doped Nitrogen-doped Activated Carbon, Sugarcane Bagasse, KOH and Urea Activation, $\mathrm{CO}_{2}$ Adsorption.

\section{INTRODUCTION}

$\mathrm{T}^{\mathrm{i}}$ he Carbon dioxide $\left(\mathrm{CO}_{2}\right)$ is one of the greenhouse gases that contributes the most to the occurrence of the greenhouse effect. About $70 \%$ of carbon dioxide gas is produced as a by-product of activities carried out by humans. Over the past two decades, the greenhouse effect caused an increase in the average temperature of the earth's surface around $0.8^{\circ} \mathrm{C}$ with an increase in the concentration of $\mathrm{CO}_{2}$ in the atmosphere from $280 \mathrm{ppm}$ to 400 ppm until May 2013. The $\mathrm{CO}_{2}$ gas increase is estimated to reach $1550 \mathrm{ppm}$ by 2030 if $\mathrm{CO}_{2}$ gas emissions are not controlled. In addition to causing global warming, carbon dioxide dioxia that exceeds the normal limit (350 ppm) can endanger health and cause acid rain which adversely affects environmental equilibrium Therefore, an effort is needed that can control emissions $\mathrm{CO}_{2}$ gas in the air [1][2].

The technology that is widely developed to control $\mathrm{CO}_{2}$ gas emissions is Carbon Capture and Storage (CCS), which is a method of separating carbon dioxide from the air through the process of capturing $\mathrm{CO}_{2}$ gas on a large scale and then flowed and stored into a porous material so that $\mathrm{CO}_{2}$ gas will not be released back into the atmosphere.

The CCS method is between absorption, cryogenic distillation, membrane and adsorption. The absorption method has a high efficiency (>90\%) but requires high costs and energy consumption for the regeneration process of the absorbent. Whereas the cryogenic distillation method is carried out with the principle of condensation which occurs at low temperatures $\left(-161^{\circ} \mathrm{C}\right)$ without involving solvents so that it requires high energy to decrease $\mathrm{CO}_{2}$ gas. Therefore, from the various CCS methods, the adsorption method is considered to be a potential method to be applied in reducing $\mathrm{CO}_{2}$ gas emissions because it has the advantage of requiring low costs and energy because generally the adsorption process takes place temperature and pressure [3][4].

The adsorption method has a high adsorption and desorption rate, therefore the adsorbent is easy to regenerate, has high mechanical and thermal stability and

Randy Yusuf Kurniawan, Irsandi Dwi Oka Kurniawan, Lukman Atmaja, and Nurul Widiastuti are with Department of Chemistry, Institut Teknologi Sepuluh Nopember, Surabaya, 60111. E-mail: nurul_widiastuti@chem.its.ac.id produces high adsorption capacity [3]. The adsorption process is divided into 2 parts, namely chemisorption and physical adsorption (physisorption). Physical adsorption of adsorbate $\left(\mathrm{CO}_{2}\right.$ gas) can be easily adsorbed on the surface of the adsorbent (activated carbon) through the Van der Waals force, so generally the adsorbent used will be easy to regenerate. While in chemical adsorption, there is an interaction between the adsorbate and the adsorbent on the surface which makes it difficult to regenerate [4].

$\mathrm{CO}_{2}$ gas adsorption methods can be carried out using porous materials namely mesoporous silica [5] zeolite [6], porous carbon [7], and Metal Organic Framework (MOF) [8]. From some of these materials, activated carbon is considered as a potential material to be used as $\mathrm{CO}_{2}$ gas adsorbent because of its high surface area and thermal stability, high adsorption-desorption kinetics and low cost in production. Activated carbon with a high surface area has higher $\mathrm{CO}_{2}$ gas adsorption ability than carbon nanotubes and carbon nanofiber [9]. Therefore, in this study activated carbon was used as $\mathrm{CO}_{2}$ gas adsorbent material.

The material that is widely developed for $\mathrm{CO}_{2}$ gas adsorption is activated carbon because of its high surface area and thermal stability, high adsorption-desorption kinetics and low cost production [9]. Activated carbon can be prepared from biomass waste such as oil palm shells, coconut shells, date seeds, and bagasse. In some of these biomass wastes, bagasse is a type of biomass that has the potential to be developed as raw material for the production of activated carbon because it is abundant in Indonesia, reaching 7.68 million tons of bagasse per year and contains ligninselulose biopolymers consisting from hemicellulose, lignin and cellulose which can be used as carbon sources [10][11]. Sugarcane bagasse has high hemicellulose content compared to other ligninselulose components which reaches $53.4 \%$ by weight therefore the bagasse can be converted into activated carbon through two step methods [12]. The average energy of $\mathrm{CO}_{2}$ gas adsorption on activated carbon is $-13.07 \mathrm{~kJ} / \mathrm{mol}$, therefore to get a high adsorption capacity it is necessary to increase the temperature and pressure [13]. Alternative method that can be used to increase the interaction between gas-solid by adding heteroatom to the activated carbon matrix. Strong interaction between heteroatom on activated carbon and $\mathrm{CO}_{2}$ gas is expected to increase $\mathrm{CO}_{2}$ gas adsorption capacity [14]. In previous studies several 


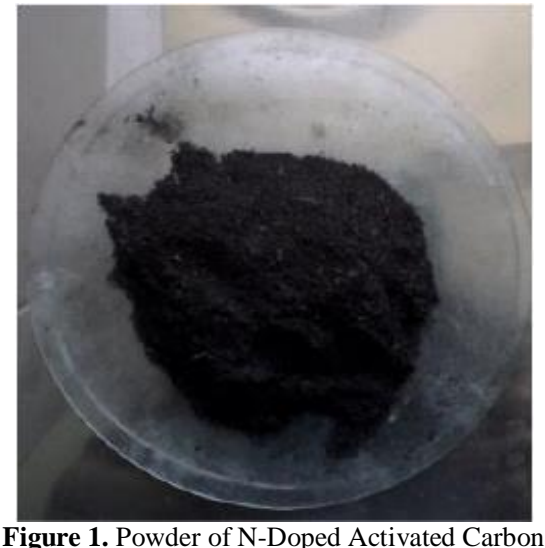

Figure 1. Powder of N-Doped Activated Carbon

heteroatoms that had been added to activated carbon were Boron (B) [15], Sulfur (S) [16] and Nitrogen (N) [17]. Nitrogen is a type of heteroatom which has the greatest effect on increasing interactions between $\mathrm{CO}_{2}$ and carbon compared to other heteroatoms [18]. One important parameter in the $\mathrm{N}$ doping process on carbon is the maximum amount of nitrogen ( $\%$ by weight $\mathrm{N}$ ) that can be doped on carbon matrix. In the previous studies explain that the presence of excess nitrogen can actually cover the carbon pore which results in a decrease in the carbon surface area of $853 \mathrm{~m}^{2} / \mathrm{g}$ at an $\mathrm{N}$ ratio of $0.1 \%$ by weight to $609 \mathrm{~m}^{2} / \mathrm{g}$ at an $\mathrm{N}$ ratio of $0.3 \%$ by weight. However, $\mathrm{N}$ $0.3 \%$ has a higher $\mathrm{CO}_{2}$ gas adsorption capacity than $\mathrm{N}$ $0.1 \%[19]$.

\section{METHOD}

\section{A. Materials}

Sugarcane bagasse was collected from Keputih, Surabaya. KOH (SAP), Deionised water, $\mathrm{H}_{2} \mathrm{SO}_{4}(98 \%$ p.a), Urea (p.a), $\mathrm{N}_{2}$ gas with high purity (HP) $(99,99 \%$ $\left.\mathrm{N}_{2}\right), \mathrm{CO}_{2}$ with Ultra High Purity (UHP) $\left(99,9999 \% \mathrm{CO}_{2}\right)$.

\section{B. Activated Carbon (SBAC) Synthesis}

The activated carbon from sugarcane bagasse was synthesized via two step methods carbonization and activation. First, the sugarcane bagasse was cut into pieces, dried in oven $\left(100^{\circ} \mathrm{C}\right)$ for $24 \mathrm{~h}$ Subsequently, the dried sugarcane bagasse was carbonized for $2 \mathrm{~h}$ at $500^{\circ} \mathrm{C}$ at heating rate $3^{\circ} \mathrm{C} \mathrm{min}^{-1}$ in $\mathrm{N}_{2}$ flow. After cooling, the obtained sample was denoted as SBC was mixed with $\mathrm{KOH}$ at ratio 1:3 (SBC: $\mathrm{KOH})$. The mixture was further activated at $750^{\circ} \mathrm{C}$ for $2 \mathrm{~h}$ at a heating rate $3^{\circ} \mathrm{C} \mathrm{min}-1$ under $\mathrm{N}_{2}$ atmosphere. The obtained product were washed several times with deionized water to remove impurities and the dried at $105^{\circ} \mathrm{C}$ for $24 \mathrm{~h}$. The obtained sample was denoted as SBAC.

\section{N-Doped Activated Carbon (SBACN) Synthesis}

The N-Doped activated carbon was synthesized via two step methods carbonization-doping and activation. First, the sugarcane bagasse was cut into pieces, dried in oven $\left(100^{\circ} \mathrm{C}\right)$ for $24 \mathrm{~h}$. Subsequently, the dried sugarcane bagasse and urea were mixed thoroughly at a ratio mass $1: 1$. The mixture was then carbonized for $2 \mathrm{~h}$ at $500^{\circ} \mathrm{C}$ at a heating rate $3^{\circ} \mathrm{C} \min ^{-1}$ in $\mathrm{N}_{2}$ flow. After cooling, the obtained sample was denoted as SBAN was mixed with $\mathrm{KOH}$ at ratio 1:3 (SBAN: $\mathrm{KOH})$. The mixture was further activated at $750^{\circ} \mathrm{C}$ for $2 \mathrm{~h}$ at a heating rate $3^{\circ} \mathrm{C} \mathrm{min}{ }^{-1}$ under $\mathrm{N}_{2}$ atmosphere. The obtained product were washed several times with deionized water to remove impurities and the dried at $105^{\circ} \mathrm{C}$ for $24 \mathrm{~h}$. The obtained sampel was denoted as SBACN.

\section{N-Doped Activated Carbon (SBACN) Characterization}

The powder X-Ray diffraction (XRD) analysis were employed to identify effect of $\mathrm{N}$ to crystallography activated carbon, Scanning Electron Microscope (SEM) to study the effect of $\mathrm{N}$ to morphology of activated carbon, specific surface area and pore distribution of SBACN was determined by adsorption-desorption $\mathrm{N}_{2}$ (BET) using (Quantachrome Autosorb $i Q$ ) and the last to identify the kind of $\mathrm{N}$ bonding in the carbon matrix was used FTIR.

\section{RESULTS AND DISCUSSION}

\section{A. Synthesis of SBAC and SBACN}

N-Doped Activated carbon which successful synthesized can be shown at fig 1 . In Figure 1 shows that the bagasse charcoal produced is still rough with nonuniform charcoal size. However, the bagasse charcoal is not coarser than the charcoal produced from the coconut shell. This is because the bagasse has a lower lignin content of $15 \%$, while the coconut shell has a lignin content of $33.61 \%$. Lignin compounds are natural polymers consisting of polyphenol molecules which function as binding to wood cells to each other, so that plant stems become hard and stiff [20].

The next step is the carbonization process. First the bagasse charcoal that has been cooled is mashed by using pestle and mortar. The refining process aims to reduce the size of sugarcane charcoal. The finer (smaller) size of bagasse, then the surface area of bagasse is contacted with heat when carbonization is also getting bigger. The bagasse carbonization process is carried out at a temperature of $500^{\circ} \mathrm{C}$. The reactions that occur during the carbonization process are as follows [21]:

$$
\begin{aligned}
& \mathrm{C}_{6} \mathrm{H}_{10} \mathrm{O}_{5}(\mathrm{~s})+\mathrm{O}_{2}(\mathrm{~g}) \rightarrow \mathrm{C}_{4}(\mathrm{~S})+\mathrm{CO}(\mathrm{g})+\mathrm{CO}_{2}(\mathrm{~g})+ \\
& 5 \mathrm{H}_{2} \mathrm{O}(\mathrm{g})
\end{aligned}
$$

Based on the Reaction Equation 1, the carbonization process of bagasse produces carbon solids and other volatile compounds.Carbon products from the bagasse carbonization process are refined. Then the fine bagasse carbon is filtered using a 125 mesh filter. The refining and filtration aims to produce uniform sized carbon and reduce the particle size of the bagasse carbon. Particle size can affect carbon surface area. The smaller the particle size, the greater the surface area of carbon. Large surface area of carbon can affect the large storage capacity of hydrogen gas. Therefore, to find out the large surface area of carbon that has been produced from the carbonization process of the bagasse above can be done by measuring the surface area using the BET method. The test results using the BET method can be seen in Table 1. The results of testing the BET method on bagasse carbon showed that the surface area of sugarcane bagasse was very small at $22,5 \mathrm{~m}^{2} / \mathrm{g}$. Large surface area on carbon can affect the formed pore structure. The smaller the surface area of carbon, the greater the pore structure produced.To enlarge the surface area of carbon produced from bagasse, it can be done with a chemically activated treatment.

Carbon activation in this study aims to enlarge the surface area of carbon by changing the macropore 


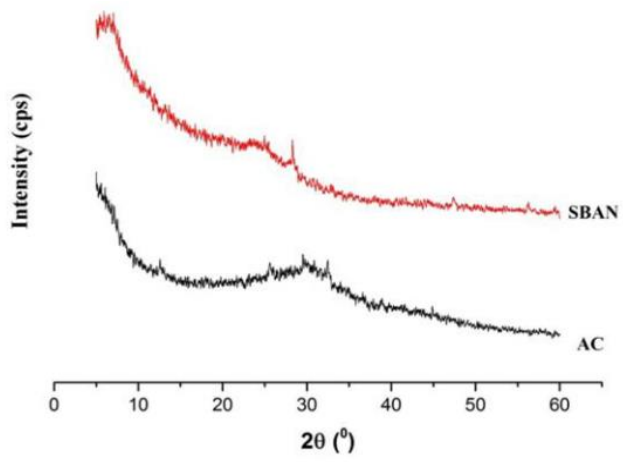

(a)

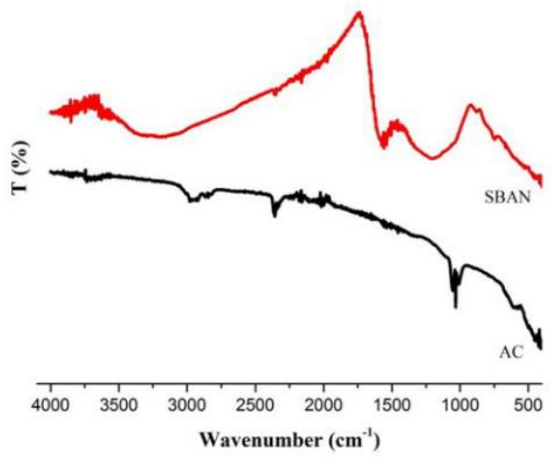

(b)

Figure 2. (a) Diffractogram (b) FTIR Spectra of SBACN and Pristine Activated Carbon from Sugarcane Bagasse.

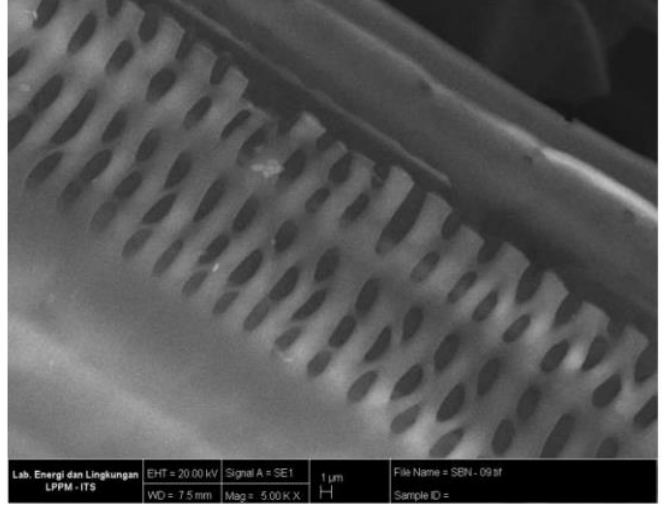

(a)

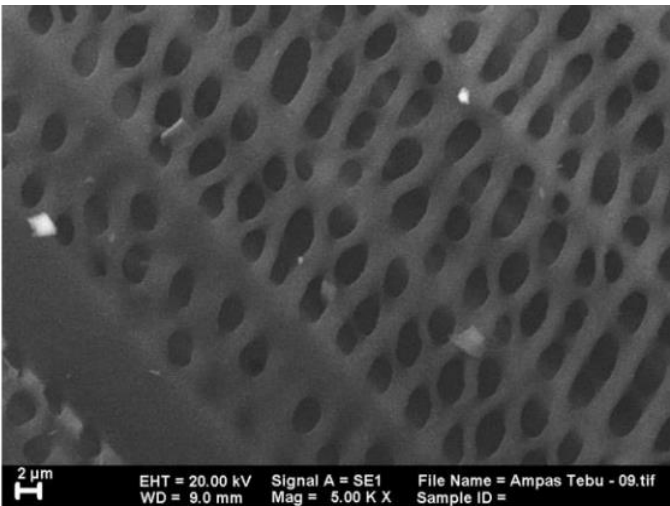

(b)

Figure 3. SEM Image of (a) SBAC (b) SBACN

structure of carbon into a micropore structure. The activation method chosen is the chemical activation method. The advantages of chemical activation methods compared to physics activation methods include lower activation temperature, higher yield of activated carbon and more formed pores. The activator substance used in this study was $\mathrm{KOH}$. $\mathrm{KOH}$ is a hydrating agent at high temperatures so that it can be used as an activator in the chemical activation process. $\mathrm{KOH}$ activators can increase the surface area in several studies. The large surface area will increase hydrogen adsorption capacity. $\mathrm{KOH}$ will be able to easily react with lignocellulose material on bagasse which has been carbonized beforehand [22]. This is different from acidic activators such as $\mathrm{ZnCl}_{2}$, material which has lignocellulose compound is better mixed directly with $\mathrm{ZnCl}_{2}$ activator without going through the previous carbonization process. This is because the lignocellulose material contains a lot of oxygen and acids will react well with functional groups containing oxygen [23].

The thing that must be considered in the activation process is the amount of activator added to carbon. The carbon/KOH ratio can affect hydrogen adsorption capacity. The number of suitable activators can increase the carbon dioxide adsorption capacity. However, if the number of activators is less or even excessive, it can reduce the adsorption capacity of $\mathrm{CO}_{2}$ gas on carbon [23]. Therefore, in this study a variation of the carbon / $\mathrm{KOH}$ ratio was carried out to determine the right amount of $\mathrm{KOH}$ to the optimal $\mathrm{CO}_{2}$ adsorption capacity of the bagasse activated carbon.

Carbonization is carried out at a temperature of $750{ }^{\circ} \mathrm{C}$. The temperature of $750^{\circ} \mathrm{C}$ is the optimal temperature of carbonization in lignocellulose material [23]. If the carbonization temperature is too high it will damage the pore structure formed on carbon. The pore structure is possible to be damaged at temperatures above $750^{\circ} \mathrm{C}$ so that it can reduce porosity in carbon [24]. Chemical reactions that occur at the time of carbonization according to [25] are as follows:

$$
\begin{aligned}
& 4 \mathrm{KOH}(\mathrm{aq})+\mathrm{C}(\mathrm{s}) \rightarrow \mathrm{K}_{2} \mathrm{CO}_{3}(\mathrm{aq})+\mathrm{K}_{2} \mathrm{O}(\mathrm{aq})+2 \mathrm{H}_{2}(\mathrm{~g}) \\
& \mathrm{K}_{2} \mathrm{CO}_{3}(\mathrm{aq})+2 \mathrm{C}(\mathrm{s}) \rightarrow 2 \mathrm{~K}(\mathrm{~s})+3 \mathrm{CO}(\mathrm{s}) \\
& \mathrm{K}_{2} \mathrm{CO}_{3}(\mathrm{aq}) \rightleftarrows 2 \mathrm{~K}(\mathrm{~s})+\mathrm{CO}_{2}(\mathrm{~g})+\mathrm{l}_{2} \mathrm{O}_{2}(\mathrm{~g}) \\
& 2 \mathrm{KOH}(\mathrm{aq}) \rightleftarrows \mathrm{K}_{2} \mathrm{O}(\mathrm{aq})+\mathrm{H}_{2} \mathrm{O}(\mathrm{aq}) \\
& \mathrm{K}_{2} \mathrm{O}(\mathrm{aq})+\mathrm{CO}_{2}(\mathrm{~g}) \rightleftarrows \mathrm{K}_{2} \mathrm{CO}_{3}(\mathrm{aq}) \\
& \mathrm{K}_{2} \mathrm{CO}_{3}(\mathrm{aq}) \rightleftarrows \mathrm{K}_{2} \mathrm{O}(\mathrm{aq})+\mathrm{CO}_{2}(\mathrm{~g}) \\
& \mathrm{K}_{2} \mathrm{O}(\mathrm{aq})+\mathrm{C}(\mathrm{s}) \rightleftarrows 2 \mathrm{~K}(\mathrm{~s})+\mathrm{CO}(\mathrm{g})
\end{aligned}
$$

Based on these reactions, the carbonization process produces several compounds including carbon dioxide gas, water vapor and carbonate compounds. At the time of carbonization, carbon dioxide gas can react again with $\mathrm{KOH}$ to produce carbonate compounds again. The above reaction also produces water vapor, because $\mathrm{KOH}$ is a hydrating agent. Potassium atoms formed during the carbonization process will experience good intercalation to develop and form micropores on carbon.

The use of $\mathrm{KOH}$ is considered more environmentally friendly than $\mathrm{ZnCl}_{2}$ and $\mathrm{H}_{3} \mathrm{PO}_{4}$ [24]. Therefore, $\mathrm{KOH}$ is a type of activator that is widely used as a pore control agent. $\mathrm{KOH}$ activators are also considered to be more effective in producing activated carbon with micropore distribution and high surface area up to $3000 \mathrm{~m}^{2} / \mathrm{g}$. Serafin synthesized activated carbon through activation using $\mathrm{KOH}$ and obtained an adsorption capacity of $21.2 \%$ at 298 $\mathrm{K}$ and a low pressure of 1 bar [16]. Meanwhile, other studies obtaining carbon that was activated using $\mathrm{KOH}$ had a higher surface area of $6.91 \%$ higher when compared to activation using $\mathrm{H}_{3} \mathrm{PO}_{4}$ [25]. The mass ratio and activation temperature can be said to be optimal if it 
TABLE 1.

SPECIFIC SURFACE AREA AND PARAMETER POROSITY OF SBAC AND SBACN

\begin{tabular}{cccc}
\hline \hline Sample & $\begin{array}{c}\text { SBET } \\
\left(\mathbf{m}^{2} / \mathbf{g}\right)\end{array}$ & $\begin{array}{c}\text { Vmikro } \\
\left(\mathbf{c m}^{3} / \mathbf{g}\right)\end{array}$ & $\begin{array}{c}\mathbf{V t} \\
\left(\mathbf{c m}^{\mathbf{3}} / \mathbf{g}\right)\end{array}$ \\
\hline SBAC & 212,76 & 0,062 & 0,112 \\
SBACN & 301,34 & 0,103 & 0,146 \\
\hline \hline
\end{tabular}

produces carbon with a high surface area and micropore distribution and of course produces a high adsorption capacity. This is because micropore is one of the most important factors in the gas adsorption process, so it is very important to produce adsorbent material with a high level of proosity (micropore) [26]. In the previous study, activated carbon prepared from rice husk ash and activated using $\mathrm{KOH}$ with a mass ratio of $\mathrm{KOH} / \mathrm{C}$ 3: 1 at $750^{\circ} \mathrm{C}$ had a surface area of $1935.8 \mathrm{~m}^{2} / \mathrm{g}$, micropore volume of $0.807 \mathrm{~cm}^{3} / \mathrm{g}$ and gas adsorption capacity $\mathrm{CO}_{2}$ is $22.2 \%$ by weight at $30^{\circ} \mathrm{C}$ and a pressure of 1 bar [25]. Hidayatullah, synthesizes activated carbon from bagasse with variations of $\mathrm{KOH} / \mathrm{C} 1: 1$ at $800^{\circ} \mathrm{C}$ activation temperature and obtained a small surface area of $178 \mathrm{~m}^{2} / \mathrm{g}$. Another study conducted by Geng et al. 2015 obtained activated carbon material with a high surface area and micropore volume of $2613 \mathrm{~m}^{2} / \mathrm{g}$ and $0.269 \mathrm{~cm}^{3} / \mathrm{g}$ through activation using $\mathrm{KOH}$ with a ratio of $3: 1$ and activation temperature of $800^{\circ} \mathrm{C}$. The resulting micropore volume is the largest volume value compared to activated carbon with variations of $\mathrm{KOH} / \mathrm{C} 4: 1$ and 5: 1 at the same temperature.

The $\mathrm{CO}_{2}$ gas adsorption mechanism on activated carbon occurs through the weak Van der Waals interaction between $\mathrm{CO}_{2}$ molecules and the surface of the activated carbon. $\mathrm{CO}_{2}$ gas adsorption in activated carbon material is based on the principle of fissization (physical adsorption) which is a reversible absorption of $\mathrm{CO}_{2}$ molecules on the surface of the adsorbing material. The adsorption material acts as an adsorbent, while carbon dioxide acts as an adsorbate. $\mathrm{CO}_{2}$ gas initially enters the pore on the surface of the adsorbent and occupies the pore on the surface of the adsorbent and occupies the active active blank on the surface [27]. Continuous filling finally makes $\mathrm{CO}_{2}$ gas form a monolayer layer (4) above the surface of the adsorbent. If this condition is continued, $\mathrm{CO}_{2}$ gas will form a multilayer layer until it reaches a saturation level [27]. If the adsorbed $\mathrm{CO}_{2}$ gas has reached its saturation point, then the adsorption capacity will decrease due to the attraction between the surface and the adsorbate decreases as the adsorbent surface has been covered by the adsorbate molecule which has stuck to the surface of the adsorbate. The phenomenon of saturation is indicated by a graph that starts straight which shows the value of capacity (q) that begins to reach equilibrium $\left(\mathrm{q}_{\mathrm{e}}\right) . \mathrm{CO}_{2}$ gas adsorption capacity on activated carbon is determined by the gravimetric method [30], which is by observing changes in mass during the $\mathrm{CO}_{2}$ gas absorption process and then calculating the difference between the initial mass (mass before gas flow). Gravimetric measurements are expressed in \% by weight according to equation (2.3). Where $\mathrm{mt}$ is the sample mass after $\mathrm{CO}_{2}$ gas adsorption while $\mathrm{m} 0$ is the initial sample mass.

\section{B. Characterization of $S B A C$ and $S B A C N$}

Fig 2 (a) shows the XRD pattern for pristine activated carbon and $\mathrm{N}$ doped activated carbon (SBACN). The figures showed all samples show the broadened

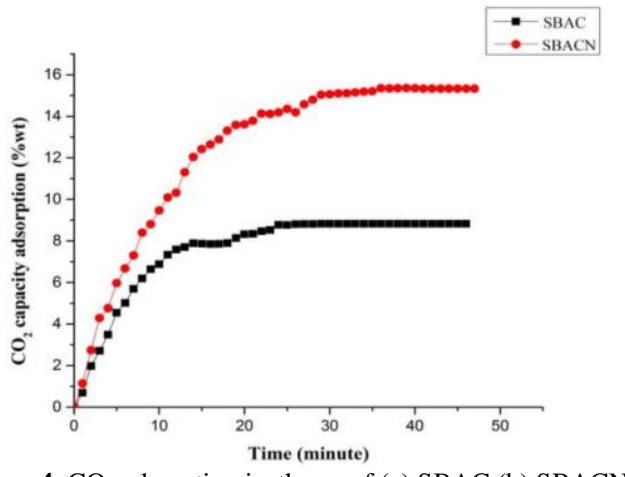

Figure 4. $\mathrm{CO}_{2}$ adsorption isotherm of (a) SBAC (b) SBACN.

diffraction reflections, which were centered at around $2 \theta=$ $31,2^{\circ}$ for activated carbon and $28,3^{\circ}$ for SBACN due to reflection to the (002) palnes of graphite, showing their dominant features of amorphous carbon. For the SBACN sample, the (002) plane shift to smaller angle as compared with pristine activated carbon, indicating a low degree of crystallinity and graphitization on $\mathrm{N}$-doped activated carbon, which may due to the existence of more pores and defects derived from the synergistic activation effect of $\mathrm{KOH}$ and urea. The FTIR spectra of pristine activated carbon and SBACN were shown in fig 2 (b). For SBACN, the peak at 1454 and $1538 \mathrm{~cm}^{-1}$ atribut to $\mathrm{N}-\mathrm{CH}_{2}$ and $\mathrm{C}=\mathrm{N}$ bonding suggesting that nitrogen atom not only exist in the surface of activated carbon but also exist in the SBACN polyaromatic structure. The peak at $3212 \mathrm{~cm}^{-1}$ is due to N-H-O-H stretching [28].

In order to elucidate the role of urea as $\mathrm{N}$ source in the pyrolysis process, the SEM images of $\mathrm{N}$-doped activated carbon are shown in fig 3 , the SBACN displays a rough structure with interconnected porous network and hierarchical pore structure. Moreover, we can observe existence of large number of micropores from the SEM image. The previous study conclude that the addition of urea on activated carbon will displays very thin layered carbon morphology, show interconnected meso- and microporous network structure without obvious macropores rather than pristine activated carbon [28].

In this study, SBAC and SBACN were tested for $\mathrm{CO} 2$ gas adsorption capacity. The process of measuring $\mathrm{CO} 2$ gas adsorption capacity was tested by the gravimetric method, namely by observing changes in mass during the $\mathrm{CO} 2$ gas absorption process and recorded every 1 minute, then calculated the difference between the initial mass (mass before gas flow). The results of measurement of $\mathrm{CO}_{2}$ gas adsorption capacity in SBAC and SBACN materials are then converted to weight percent. Before testing $\mathrm{CO}_{2}$ gas adsorption capacity, SBAC and SBACN carried out the degassing process at $350^{\circ} \mathrm{C}$ for 3 hours to remove impurities and water vapor. After the degassing process the temperature is reduced to room temperature $\left(30^{\circ} \mathrm{C}\right)$, then the $\mathrm{CO}_{2}$ gas adsorption process begins with a flow rate of $10 \mathrm{~mL} /$ minute which is set using the Mass Flow Control tool. In this study the $\mathrm{CO}_{2}$ gas adsorption process was carried out at $30^{\circ} \mathrm{C}$ until the mass of the adsorbent was constant. The Results of determined $\mathrm{CO}_{2}$ gas adsorption capacity are shown in Figure 4. Based on Figure 4, the $\mathrm{CO}_{2}$ adsorption capacity pattern in each sample has similarities as increasing hydrogen adsorption, which tends to increase. In the 0th minute until the $23^{\text {rd }}$ minute there was a sharp increase, meaning that the $\mathrm{CO}_{2}$ 


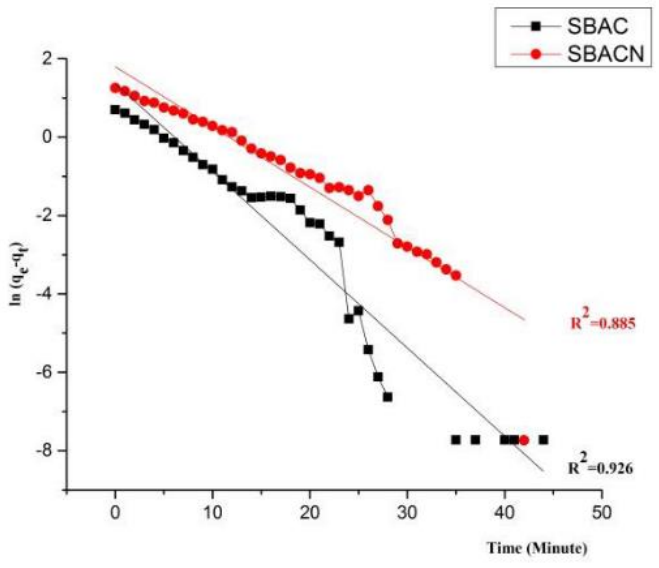

(a)

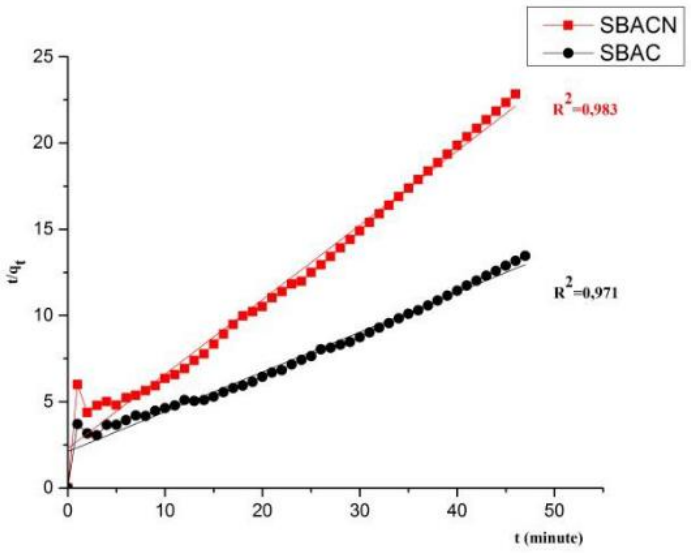

(b)

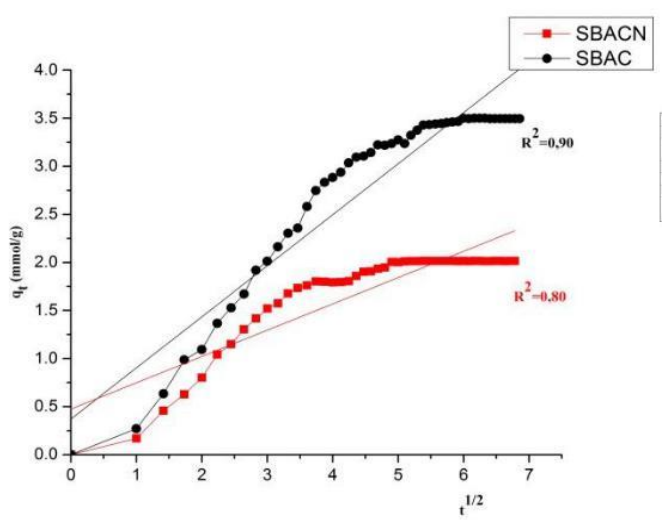

(c)

Figure 5. Graph of Isotermal $\mathrm{CO}_{2}$ adsorption kinetic model: (a) pseudo-first order (b) pseudo-second order (c) intraparticle diffusion.

gas adsorption process took place quickly. This is because at the beginning of adsorption, $\mathrm{CO}_{2}$ gas enters the pore and occupies an empty active side on the carbon surface. In this condition, the $\mathrm{CO}_{2}$ gas adsorption process starts to run slowly because the empty active side has been filled by the incoming $\mathrm{CO}_{2}$ gas first [24]. This process is seen in Figure 4 , where from the $24^{\text {th }}$ minute the increase in $\mathrm{CO}_{2}$ adsorption capacity occurs slowly. If this condition is continued, $\mathrm{CO}_{2}$ gas will form a multilayer layer until it reaches a saturation level [24]. The saturation level is indicated by the mass obtained constant.

The pristine activated carbon has a lower adsorption capacity than SBACN which suggest that pristine activated carbon displays more obvious mesoporous and macroporous character than microporous. The presence of pores less than $2 \mathrm{~nm}$ is an important parameter in adsorbing gas because the density of the gas will increase when it is in the micropore therefore the gas will not be easily released [29]. These results are also supported by testing using SEM where after doping, micropore distribution increases. These results suggest that both $\mathrm{KOH}$ and urea can act as efficient chemical activation reagents for improving the porosity and specific surface area of the carbon materials. The value of $\mathrm{CO}_{2}$ gas adsorption capacity on SBAC and SBACN at temperature and space pressure respectively were 7.07 and $11.20 \mathrm{wt} \%$ (Fig. 3).This value is slightly smaller than that the porous carbon obtained from ammonia dopant of palm shell [30] and resin formaldehyde [31].

The lower $\mathrm{CO}_{2}$ gas adsorption capacity on SBAC material when compared to SBACN because the effect of nitrogen adds to the active side while increasing the new pore, resulting in additional surface area and micropore volume. the interaction of SBAC and SBACN carbon with $\mathrm{CO}_{2}$ gas molecules as atoms has almost the same electronegativity, so that carbon bonds with $\mathrm{CO}_{2}$ generally do not have large bonded dipole moments [17]. Therefore, hydrogen molecules can maintain their properties and do not change when the adsorption process takes place. Porous carbon has a hexagonal structure such as benzene with $\mathrm{sp}^{2}$ hybridization. The hydrogen bond in the $\mathrm{sp}^{2}$ hybridization system has a weak interaction, which results from dipole-dipole induction. The dipole moment produced is very small because the bond between $\mathrm{H}-\mathrm{H}$ molecules originating from the amine group on the SBACN is quite rigid and the load density of the material bound to $\mathrm{sp}^{2}$ is slightly uniform at the equilibrium of $\mathrm{CO}_{2}$ adsorption, causing an increase in $\mathrm{CO}_{2}$ molecules in low carbon [17].Therefore in this study nitrogen modification was carried out.

In addition to the proportion of micropores that are higher than activated carbon (SBAC), the $\mathrm{N}$ atoms in SBACN also influence the adsorption capacity of the $\mathrm{CO}_{2}$. $\mathrm{CO}_{2}$ gas is a species of weak acid molecule that can interact with the free electron pair found on the $\mathrm{N}$ atom. This interaction is Lewis acid-base. In the previous study, $\mathrm{N}$ atoms were types of atoms which had a large influence on increasing $\mathrm{CO}_{2}$ gas adsorption capacity through Lewis acid-base interactions where $\mathrm{CO}_{2}$ acts as an acid while $\mathrm{N}$ is a base species that donates free electron pairs to $\mathrm{CO}_{2}$ molecules [31]. This interaction causes more $\mathrm{CO}_{2}$ gas to be adsorbed through chemical adsorption interactions. Therefore, the SBACN type of adsorption produced is a combination of physical and chemical adsorption. This 
type of adsorption also causes the equilibrium adsorption point on SBACN to be longer than SBAC. In Figure 4, it can be seen that the SBACN equilibrium point occurred at the 23 minute while the SBAC at the 17 minute showed the equilibrium point. This shows that the SBAC adsorption occurs only involving the role of the pore while the role of SBACN $\mathrm{N}$ also helps the $\mathrm{CO}_{2}$ gas adsorption process so that when $\mathrm{CO}_{2}$ gas has filled the entire pore of activated carbon, then $\mathrm{CO}_{2}$ will interact with the $\mathrm{N}$ atom. This gives an advantage over physical adsorption which only involves the role of porosity. The type of physical adsorption has a low adsorption enthalpy value which causes $\mathrm{CO}_{2}$ gas to be more easily decomposed and this decreases its function as a gas adsorbent if applied on a large scale.

Increased $\mathrm{CO}_{2}$ gas adsorption capacity on $\mathrm{N}$-doped carbon is also caused by Lewis acid-base interactions. $\mathrm{CO}_{2}$ is a weak Lewis acid that can interact with Lewis base species. The Lewis base will donate electrons to the $\mathrm{CO}_{2}$ molecule. On this carbon, nitrogen will bind to $\mathrm{C}$ atoms by forming $\mathrm{N}$-pyridinic, $\mathrm{N}$-hydraulic and $\mathrm{N}$ graphitic structures. N-pyridine contains a pair of free electrons that can be donated to $\mathrm{CO}_{2}$ molecules and causes $\mathrm{CO}_{2}$ to be oxidized to form $\mathrm{CO}$ molecules or formic acids. The addition of $\mathrm{N}$ to the surface of activated carbon can increase electronic conductivity and surface alkalinity. Increased resistance to the surface of activated carbon will increase interaction with Lewis acid species such as $\mathrm{CO}_{2}$ [17].

Previous study was found that the addition of nitrogen atoms to activated carbon produced $\mathrm{CO}_{2}$ gas adsorption capacity of $1.73 \mathrm{mmol} / \mathrm{g}$ at $25^{\circ} \mathrm{C}$ and 1 bar pressure. This value is higher than activated carbon without $\mathrm{N}$ doping which only produces $\mathrm{CO}_{2}$ gas adsorption capacity of 1.22 $\mathrm{mmol} / \mathrm{g}$. Hao, et al., 2010 [36] reported that activated carbon $\mathrm{N}$-doped from monolith had a higher $\mathrm{CO}_{2}$ gas adsorption capacity of $3.3 \mathrm{mmol} / \mathrm{g}$ at $25^{\circ} \mathrm{C}$ than activated carbon that was prepared from melamine $(2.25 \mathrm{mmol} / \mathrm{g})$. The same results were also reported by [32] who found an increase in $\mathrm{CO}_{2}$ gas adsorption capacity of $32 \%$ on $\mathrm{N}$ doped activated carbon compared to activated carbon without $\mathrm{N}$ dopant.

The adsorption of $\mathrm{CO}_{2}$ gas on $\mathrm{N}$ doped carbon occurs chemically through the presence of Lewis acid-base interactions. $\mathrm{CO}_{2}$ is a weak Lewis acid that can interact with Lewis base species. The Lewis base will donate electrons to the $\mathrm{CO}_{2}$ molecule. In general, $\mathrm{N}$-pyridine contains a pair of free electrons that can be donated to $\mathrm{CO}_{2}$ molecules and causes $\mathrm{CO}_{2}$ to be oxidized to form $\mathrm{CO}$ molecules or formic acids. Niu also mentioned that the addition of $\mathrm{N}$ to the surface of activated carbon can increase electronic conductivity and surface alkalinity [17]. Increased resistance to the surface of activated carbon will increase interaction with Lewis acid species such as $\mathrm{CO}_{2}$. If $\mathrm{N}$ is present in the carbon group in the form of amine, then the $\mathrm{N}$ reaction on the amine group with $\mathrm{CO}_{2}$ gas molecules can be stated as follows:

The reaction can be seen in $\mathrm{CO}_{2}$ gas which interacts with $\mathrm{N}$ atoms in the amine group to form a product in the form of ammonium carbamate and ammonium bicarbonate. The previous research found that one bidentate ammonium carbamate molecule can be converted into two bidentate ammonium bicarbonate molecules when water vapor is flowed into the system. The $\mathrm{CO}_{2}$ gas adsorption capacity of $\mathrm{N}$ doped carbon is also very dependent on the type of $\mathrm{N}$ bound to the carbon surface. Although $\mathrm{N}$ doping is carried out using materials containing $\mathrm{N}$ in high quantities, but if $\mathrm{N}$ is bound to carbon is a stable type of $\mathrm{N}$ quarter then of course, $\mathrm{CO} 2$ gas cannot interact with that $\mathrm{N}$ which results in low adsorption capacity values. However, if $\mathrm{N}$ bound to the surface of the carbon forms a $\mathrm{N}$-pyridin or hydraulic-like structure, then the structure will have an effect on the adsorption capacity of the $\mathrm{CO}_{2}$ produced [33].

The mechanism of interaction between $\mathrm{CO}_{2}$ molecules and $\mathrm{N}$ on $\mathrm{N}$ doped carbon can also occur through hydrogen bonds. The hydrogen bond occurs between $\mathrm{O}$ atoms in $\mathrm{CO}_{2}$ molecules with $\mathrm{H}$ or $\mathrm{N}$ atoms on the carbon surface. The structure of graphite on carbon will bind hydrogen atoms in the form of $\mathrm{C}-\mathrm{H}$ sp2 so that this $\mathrm{H}$ atom can interact in the form of hydrogen bonds with $\mathrm{O}$ atoms on $\mathrm{CO}_{2}$ molecules. In addition to $\mathrm{H}$ in the structure of graphite, if $\mathrm{N}$ also binds $\mathrm{H}$ to form an amine group then $\mathrm{H}$ can also interact with $\mathrm{O}$ atoms on $\mathrm{CO}_{2}$ molecules. This hydrogen bond can be beneficial in terms of application because $\mathrm{CO}_{2}$ gas adsorbed on the carbon surface will not be easily decomposed due to the higher bond energy value compared to the Van Der Waals interaction produced between the carbon pore structure and the $\mathrm{CO}_{2}$ gas molecule. Therefore. The adsorption capacity will increase in the surface of activated carbon.

\section{Kinetic Study of $\mathrm{CO}_{2}$ adsorption on SBAC and SBACN}

Adsorption kinetics study in this study aims to determine the effectiveness of hydrogen gas adsorption on activated carbon from bagasse. Several adsorption kinetics models have been calculated to determine the appropriate adsorption kinetics model, including: Pseudo Lagergren, Pseudo Ho, and intraparticle diffusion models.

Pseudo-first-order reactions are derivatives of second order assuming one reactant has a much higher concentration than the concentration of other reactants [34]. This kinetic modeling assumes that the reaction rate of the second order is as if it were first order. Therefore pseudo words appear in this order reaction because the concentration of one reactant does not seem to change [34][35]. Graph of pseudo-first order of SBAC and SBACN are shown in Fig. 5 (a).

In figure 5 (a) shows a graph of a pseudo-first order, which is a plot between $\ln \left(\mathrm{q}_{\mathrm{e}}-\mathrm{q}_{\mathrm{t}}\right)$ as an ordinate and time (t) as an abscissa. The quasi-order modeling in this study was that the concentration of the activated carbon adsorbent and activated carbon doped with nitrogen was assumed to be unchanged, because the concentration was too large compared to the $\mathrm{CO}_{2}$ concentration as the adsorbate.

Second-order reactions are derivatives from first order based on equilibrium adsorption capacity, assuming the adsorption capacity is always proportional to the number of active sides of an adsorbent [34]. Pseudo-second-order kinetic equations show how the adsorption rate of an adsorbate depends on the absorption capacity of the adsorbent not on the adsorbate concentration [36]. In this study, $\mathrm{CO}_{2}$ adsorption capacity is always proportional to the amount of active nitrogen in SBAC and SBACN.

The plot between $\mathrm{t} / \mathrm{q}_{\mathrm{t}}$ and time $(\mathrm{t})$ as shown in Figure 5 (b) is a pseudo second order graph. $\mathrm{CO}_{2}$ gas adsorption rate is greater in SBACN material than SBAC. Addition 
of $\mathrm{N}$ can increase $\mathrm{CO}_{2}$ adsorption capacity so that $\mathrm{CO}_{2}$ adsorption rate also increases. This shows that the adsorption process takes place faster with the addition of heteroatom $\mathrm{N}$ because nitrogen is the active side of the carbon framework.

The intra-particle diffusion kinetics model indicates the $\mathrm{CO}_{2}$ adsorption process in the SBAN pore takes place in two stages, namely the mesopore diffusion stage and the micropore diffusion stage. At the mesoporous diffusion stage, $\mathrm{CO}_{2}$ gas molecules are adsorbed on amorphous carbon on the outer surface of SBACN, while at the micropore diffusion stage, $\mathrm{CO}_{2}$ gas molecules will be deposited on the surface in the SBACN which enters the carbon pore [34][37].

The plot between $\mathrm{q}_{\mathrm{t}}$ as ordinate and $\mathrm{t}^{1 / 2}$ as abscissa as shown in Figure 5 (c) is a graph of intra-particle diffusion. Based on Figure 5 (c), the initial process or mesoporous diffusion is rapid which then slows down when diffusing into the surface of micropore diffusion on SBACN nitrogen which enters the carbon pore [34][37].

\section{CONCLUSION}

$\mathrm{N}$-doped activated carbon has been synthesized from sugarcane bagasse via 2 two-step methods successfully provide higher porosity and $\mathrm{CO}_{2}$ gas adsorption performances than activated carbon without dopant $\mathrm{N}$. The incorporation of $\mathrm{KOH}$ and urea on carbon has positive synergistic to form microporosity and effective nitrogen-doping formation. $\mathrm{N}$-doped activated carbon showed more microporosity intensity with the $\mathrm{CO}_{2}$ gas adsorption capacity produced is $11,20 \% \mathrm{wt}$.

\section{AKNOWLEDGEMENT}

The present work was financially supported by Ministtry of Higher Education, Research and Technology Indonesia, Laboratory of Chemical Material and Energy Institut Teknologi Sepuluh Nopember Surabaya

\section{REFERENCES}

[1] J. D. Figueroa, T. Fout, S. Plasynski, H. McIlvried, and R. Srivastava, "Advances in CO2 capture technology-The U.S. Department of Energy's Carbon Sequestration Program," Int. J. Greenh. Gas Control, vol. 2, pp. 9-20, 2008.

[2] H. Yang et al., "Progress in carbon dioxide separation dan capture: A review," J. Environ. Sci., vol. 20, pp. 14-27, 2008.

[3] N. Hedin, L. Andersson, L. Bergström, and J. Yan, "Adsorbents for the post-combustion capture of $\mathrm{CO} 2$ using rapid temperature swing or vacuum swing adsorption," Appl. Energy, vol. 104, pp. 418-433, 2013.

[4] Y. P. Zhang and L. Lynd, "Toward an Aggregated Understanding of Enzymatic Hydrolysisof Cellulose:Noncomplexed Cellulase Systems," Biotechnol. Bioeng., vol. 88, pp. 1-28, 2014.

[5] F. Chang, K. Chao, H. Cheng, and C. Tan, "Adsorption of CO2 onto amine-grafted mesoporous silicas', Separation dan Purification Technology," Sep. dan Purif. Technol., vol. 70, pp. 87-95, 2009.

[6] F. Akhtar, Q. Liu, N. Hedin, and L. Bergstrom, "Strong and binder free structured zeolite sorbents with very high $\mathrm{CO} 2$ over-N2 selectivities dan high capacities to adsorb $\mathrm{CO} 2$ rapidly," Energy Environ. Sci., vol. 25, pp. 7664-7673, 2012.

[7] H. G., W. Li, D. Qian, and A. H. Lu, "Rapid Synthesis of Nitrogen-Doped Porous Carbon Monolith for CO2 Capture," Adv. Mater., vol. 22, pp. 853-857, 2010.

[8] J. Li et al., "Carbon dioxide capture-related gas adsorption dan separation in metal-organic frameworks," Coord. Chem. Rev., vol. 255, pp. 1791-1823, 2011.

[9] C. Zhao, X. Chen, C. Zhao, and Y. Liu, "Carbonation and hydration characterization of dry potassium based sorbent for
CO2 capture," Energy \& Fuels, vol. 23, pp. 1766-1769, 2009.

[10] FAO, "Mayor Food and Agricultural Commodities and Procedures: Sugarcane Bagasse," www.fao.org, 2014 [Online]. Available: http://www.fao.org/es/ess/top/commodity.html.

[11] S. Vassilev, "An overview of the chemical composition of biomass," Fuel, vol. 89, pp. 913-933, 2010.

[12] D. Bhattacharya, L. Germinario, and W. Winter, "Isolation, preparation and characterization of cellulose microfibers obtained from bagasse," Carbohydr. Polym., vol. 73, pp. 371377, 2008.

[13] H. Yi et al., "Adsorption separation of $\mathrm{CO} 2, \mathrm{CH} 4$ and $\mathrm{N} 2$ on microwave activated carbon," J. Chem. Eng., vol. 215, pp 635-642, 2013.

[14] T. Bandosz, M. Seredych, R. Castellon, Y. Cheng, L. Daemen, and R. Cuesta, "Evidence for $\mathrm{CO} 2$ reactive adsorption on nanoporous S- and N-doped carbon at ambient conditions," Carbon N. Y., vol. 96, pp. 856-863, 2016.

[15] J. Dai, J. Yuan, and P. Giannozzi, "Gas adsorption on graphene doped with B, N, Al, and S : A theoretical study," Appl. Phys. Lett., vol. 95, pp. 10-13, 2009.

[16] M. Sevilla, B. Parra, and B. Fuertes, "Assessment of the role of micropore size and $\mathrm{N}$-doping in $\mathrm{CO} 2$ capture by porous carbons," Artik. Inst. Nac. del Carbón, pp. 1-27, 2013.

[17] Q. Niu, "Large-size graphene-like porous carbon nanosheets with controllable N-doped surface derived from sugarcane bagasse pith/chitosan for high performance supercapacitors," Carbon N. Y., pp. 1-34, 2017.

[18] Z. Liu et al., "The fabrication of porous N-doped carbon from widely available urea formaldehyde resin for carbon dioxide adsorption," J. Colloid Interface Sci., vol. 416, pp. 124-132, 2014.

[19] H. Jeon, G. Min, G. Oh, C. Nah, and J. Park, "Influence of nitrogen moieties on CO2 capture of Carbon Aerogel," Carbon Lett., vol. 16, pp. 57-61, 2015.

[20] S. Rudatin, "Potensi dan Prospek Pemanfaatan Lignin dari Limbah Industri Pulp dan Kertas di Indonesia,” Ber. Selulosa, vol. 1, pp. 14-17, 1989.

[21] C. Gimba and M. Turoti, "Optimum Condition for Carbonization of Coconut Shell," Sci. Africana, pp. 12-21, 2008.

[22] Guan, T. Billy, A. L. Puziah, and Y. H. Y. Taufiq, "Physical Preparation of Actived Carbon from Sugarcane Bagasse and Corn Husk And Its Physical and Chemical Characteristics," Int. J. Eng. Res. Tech, vol. 2, no. 3, 2013.

[23] Shofa, "Pembuatan Karbon Aktif Berbahan Baku Ampas Tebu dengan Aktivasi KOH,” Jakarta, 2012.

[24] I. Susanti, "Aktivasi Karbon Bertemplat Zeolit-Y dengan KOH untuk Peningkatan Kapasitas Adsorpsi Gas CO2," Surabaya, 2016.

[25] M. Nowrouzi, H. Younesi, and N. Bahramifar, "High ef fi cient carbon dioxide capture onto as-synthesized activated carbon by chemical activation of Persian Ironwood biomass and the economic pre-feasibility study for scale-up," J. Clean. Prod., vol. 168, pp. 499-509, 2017.

[26] M. Alhassan et al., "Comparative studies of CO2 capture using acid and base modified activated carbon from sugarcane bagasse," Biofuels, pp. 1-10, 2017.

[27] S. S., "Pembuatan dan Karakterisasi Karbon aktif dari Batubara Riau sebagai Adsorben," Universitas Indonesia, 2008.

[28] M. Peyravi, "Synthesis of nitrogen doped activated carbon/polyaniline material for CO2 adsorption," Polym. Adv. Technol., vol. 29, pp. 319-328, 2018.

[29] Z. Geng, "Pore size effect on nanoporous carbon with ultrahigh surface area on high-pressure hydrogen storage," $J$. Energy Chem., vol. 24, pp. 1-8, 2015.

[30] M. Shafeeyan, W. Daud, A. Shamiri, and N. Aghamohammadi, "Modelling of Carbon dioxide adsorption onto ammonia-modified activated carbon: kinetic analysis and breakthrough behavior," 2017.

[31] D. Tiwari, H. Bhunia, and K. Bajpai, "Development of chemically activated $\mathrm{N}$-enriched carbon adsorbents from urea formaldehida resin for $\mathrm{CO} 2$ adsorption: kinetics, isotherm and thermodynamics studies," J. Environ. Manage., vol. 218, pp. 579-592, 2018.

[32] J. Chen et al., "Enhanced CO2 Capture Capacity of NitrogenDoped Biomass-Derived Porous Carbons," ACS Sustain. Chem. Eng, pp. 1-7, 2016.

[33] D. Leung, G. Caramanna, and M. Maroto-Valer, "An overview of current status of carbon dioxide capture and 
storage technologies," Renew. Sustain. Energy Rev., vol. 39, pp. 426-443, 2014

[34] N. Widiastuti, H. Wu, H. Ang, and M. Zhang, "Removal of ammonium from grey water using natural zeolite," Desalination2, vol. 277, pp. 15-23, 2011.

[35] R. Holle, D. W. Audy, and Meiske S, "Kinetika Adsorpsi Gas Benzen pada Karbon Aktif Tempurung Kelapa," J. Hazard Mater, vol. 36, pp. 681-689, 2006.
[36] Y. Ho, "Review of Second-order Models for Adsorption Systems," J. Hazard, vol. 36, pp. 681-689, 2006.

[37] R. Kurniawan, Q. Romadiansyah, D. Tsamarah, and N. Widiastuti, "Synthesis of Zeolite-X from Bottom Ash for H2 Adsorption," J. Mater. Sci. Eng., vol. 299, 2017. 